\title{
Performing Butler's Queer Theory in Organisation Studies: An Introduction
}

\author{
DAVIDE BIZJAK \\ davide.bizjak@unina.it \\ University of Naples Federico II
}

\begin{abstract}
The contribution of queer theory in organization is still underdeveloped. Notwithstanding the presence of empirical studies that address queer issues in management, more methodological and theoretical elements are needed in organizational frameworks. This need is highlighted through a little review of the presence of queer theory in previous organizational research. A brief reflection on Butler's tought is carried out through a conceptual framework that link organizational/individual identity to the performativity of gender. Through the concept of performativity, Judith Butler addresses the concept of a socially constructed identity into a continuous and iterative way to respect gender norms and expected actions.
\end{abstract}

\section{Introduction}

This brief reflection is based on Gender Trouble. Feminism and the subversion of identity, written by Judith Butler and published by Routledge (1999)5. This research note is aimed to understand in what extent the Butler's theories have contributed to the development of research in organisations and within which conceptual assumptions those contributions can be considered well-grounded for the development of future approaches. Despite the following notes cannot be considered as a review of the book, all the next thoughts are designed around "Gender trouble[s]".

Despite Judith Butler has been engaged too few with organizations (Borgerson, 2005), a bunch of scholars have employed the post-structuralist view of feminism and queer theory in several research experiences (Jenkins and Finneman, 2017; Fine, 2016; Pullen, Thanem and Tyler, 2016; De Souza, Rumens and Brewis, 2016; Rhodes, 2017; Rumens, 2016a; 2016b; Bendl, Fleischmann and Walenta, 2008).

The two concepts engaged in this reflection are gender and identity, that, more than being addressed respectively in the third and second part of Butler (1999), have earned much interest as key features in the issue of managing diversity in organization (Herring and Herderson, 2012; Danowitz, Hannapi-Hegger and Mensi-Klarbach, 2012; Thomas, 2008). With the aim to understand better some of the possible development of diversity management in an organisation, this contribution is structured as follows: firstly a brief

\footnotetext{
${ }^{5}$ The first edition of this book has been issued nine years before but the 1999 edition has been enriched with a new preface, which is quite significant for the aim of this contribution. In fact, it represents a scrutinised critique on the entire theoretical framework traced in the 1990 edition.
} 
conceptual review of the concepts is carried out, and then, after a synthetic introduction to Diversity Management, some of the possible development are advised.

\section{Gender}

If gender is the cultural meaning that the sexed body assumes, then a gender cannot be said to follow from a sex in any one way. Taken to its logical limit, the sex/gender distinction suggests a radical discontinuity between sexed bodies and culturally constructed genders. (Butler, 1999: 10)

The binary view in western society daily influences some of our behaviours and fosters some practices of exclusion within organisation (Gagné and Tewksbury, 1998). Gender is assumed as declined in two only ways of male/female (Dentice and Dietert, 2015; Knights, 2015). This distinction is taken for granted, designing the intelligibility of agency within our social systems (Butler, 1999).

The binary gender system wrongly combines, in a deterministic way, the visible traits of genitals and reproductive functions with a certain way to identify an individual that lives in our society. In other words, the dualistic preconception surmises that people who were born and identified as male or female may act only in a priori established ways. As underlined, such assumptions begin at birth, where the body is the only discriminant in identifying someone as male or female. The body, then, is an integral aspect of the self as presented to the world and to which the world reacts.

The binary view of the world, seen as ruled by heteronormativity and masculinity (Schilt and Westbrook, 2009), implies that those who do not perceive themselves as conforming to this binary system, live in organisations in a constant state of resistance. Butler (1999) considers how sex and gender are considered too close in our binary society, exploring the world o drag queen, that challenge the pre-constitutive view of a binary system in which the performativity confirms gender stereotype on a daily base (Spicer, Alvesson, and Karemman, 2009).

Even for protected categories of workers, gender binarism lies behind the corner. Thus, even transgender and gender non-conforming people need to categorise themselves (Rundall and Vecchietti, 2010). Therefore, as Gagné and Tewksbury (1998) argue, "while gender is an internalized sense of self, it is also a social institution that, in western societies, demands conformity to a binary system where males present themselves as masculine men and females as feminine women" (Gagné and Tewksbury, 1998: 82). Therefore, organization does not remain stable over the time but, rather, it constructs itself every day, shedding light on the more evident phenomenon of whether the recognition of the individuals' identities matters for the whole organisation as much as it matters for the individuals themselves. According to Knights (2015), it is possible to go beyond the subjectivity, looking at knowledge that derives from the individuals' representation. This representation is not limited to the categories imposed by society, but he argues for a dynamic ontology of the subject, aiming to dissolve, and not only challenge, the binary system of gender.

While most people support biological determinism, we should question whether or not biology actually determines gender identity and if it is possible to change one's sex and assume a new identity (Dentice and Dietert, 2015). Indeed, as "Butler (1999) argues that both 
sex and gender differences are equally cultural constructions but ones that are dominated by norms of heterosexuality", (Knights, 2015: 203), this entails that "dissolving binaries, by contrast, invites a collapsing of the terms so that they no longer sustain and reproduce the polarities, which reflect and reproduce the domination of discourses of masculinity" (Knights, 2015: 206).

\section{Identity}

[T] $]$ e "coherence" and "continuity" of "the person" are not logical or analytic features of personhood, but, rather, socially instituted and maintained norms of intelligibility. Inasmuch as "identity" is assured through the stabilizing concepts of sex, gender, and sexuality, the very notion of "the person"is called into question by the cultural emergence of those "incoherent" or "discontinuous" gendered beings who appear to be persons but who fail to conform to the gendered norms of cultural intelligibility by which persons are defined. (Butler, 1999: 23)

Until the 80s, the concept of identity is rightly absent in organisation studies (Anteby and Anderson, 2014). The first contribution on organisational identity is by Albert and Whetten (1985), claiming that identity is made by the most stable elements of the organisation, without which an intelligible recognition of the organisation is not feasible. Since this first contribution, Management scholars have traditionally inquired into identity, reaching the result to connect the concept of identity to almost every topic in management studies (Alvesson et al., 2008).

From the extensive literature available on this topic, might be considered interesting only those contributions that allow us to observe an interaction between identity, at the organisational level, and the construction of identity, at the individual level. Following this criterion, the concept of identity evolves, in organizational studies, from an individualistic view (Albert and Whetten, 1985; Fiol and Huff, 1992; Gioia, Schultz and Corley, 2000; Brown and Starkey, 2000) to a social one (Ashfort and Mael, 1989; Scott and Lane, 2000; Alvesson and Wilmott, 2002; Hatch 2013). These two steps in the evolution of the concept of identity can be subsumed under two broad categories: the permanence of those elements strictly linked to the organisational identity and the construction of its own social identity, where elements of the individual identity interact with the organisation, and vice versa. We refer to the two categorisations as the classical and constructivist approach.

Albert and Whetten (1985) can be considered as the pioneers of the classical approach. They were the first scholars to use the term 'organisational identity' in order to identify those elements that remain 'stable, substantial and distinctive' over the time. The concept of identity argued by Albert and Whetten (1985) is quite close to the etymology of the word 'identity': id in Latin means 'the same', enduring over the time. The authors analysed a period of economic crisis in their university, interviewing some of their colleagues and asking them what they would do and what their future plans would be in case they were fired. Their answers shed light on how the concept of identity crisis moves from individuals to organization (Hatch, 2013). From this point of view, the organisational identity becomes more visible and acknowledgeable during periods of crisis, in that precise moment when people are forced to question which elements are stable and which are not. 
Gioia, Schultz and Corley (2000) expand on Albert and Whetten's (1985) elements of stability and distinctiveness over the time in organisational identity by adding that, while an organisation might not be considered stable over time, it nevertheless preserves some of its features, thus conveying a certain halo of stability. Thus, according to Gioia, Schultz and Corley (2000), what changes are the meanings associated with those labels that represent the stable elements of the organisational identity. In other words, while individuals perceive organisations as stable, they are always at the mercy of change as the meanings associated with those labels change. Gioia, Schultz and Corley (2000) call this process "adaptive instability" (Gioia, Schultz and Corley 2000: 63), which allows organisation's members to interpret certain organisational labels, in order to increase their self-esteem (Brown and Starkey, 2000). The next step is to understand how much stable the identity has to be. Is it necessary that organisational stability is saved over time or not? Are there any particular moments or circumstances in which these characteristics may change?

Corley and Harrison (2009) state that organisations need to change in order to preserve their own identity. Therefore, identity is not only an individual issue but a collective one. Therefore, it is strictly correlated with the interaction among individuals and the interaction between individuals and the organisation in the wider social context. Likewise, the organisation's identity is of significance for all the individuals belonging to that organisation and, correspondingly, individuals' identity is of paramount significance for the organisation. The constructivist approach assumes that the social context is a lever for the shaping of identity. Indeed, the Social Identity Theory (Ashfort and Mael, 1989) argues that the individual tries to obtain a better social identity thanks to the feeling of belongingness to groups that are highly considered. Organisation's members face a social identification process through the organisational identity. Thus, people who are undergoing a process of identity (gender) transition or those who are planning to do so should be valued by managers and by all the organisation's members. "[T]heories and research suggest that members' identities and organisational identity are closely linked" (Scott and Lane, 2000, p. 43). Therefore, for Judith Butler identity is considered as an effect rather than a cause (Butler, 1999). Indeed, from a Butlerian point of view, we could consider identity as socially construct, although each identity is influenced by the heteronormative matrix; a kind of prediscursive dimension that influences both the perception of performativity. The study of human relation at work have taken advantage of the methodological potential of both performativity and undoing (Riach, Rumens and Tyler, 2016). The methodological concern of performativity is fostered thanks to the logic issue about the not-queered sampling and analysis of the queer issues (De Souza, Rumens and Brewis, 2016). In Laine et al. (2016) an application of performativity to organisational identity is carried out. The concept of identity in organisations has been explored through the observation of the dynamic between the strategic actions and the institutional context. In that sense, it is making strategy in itself that contribute to the construction of the strategists' identities.

\section{Gender identity in the workplace: a managerial issue?}

Diversity management studies are currently polarised on at least two approaches (Tatli, 2010): a critical approach where discrimination between groups is criticised and a mainstream approach in which all the solutions and the practices adopted in managing diversity are compared with performances. Establishing a relationship between diversity 
and performance makes difficult affecting with different dimensions. Diversity management deals with age, race, nationality, disability and sexual orientation, (Salomon and Schork, 2003). Therefore, gender and identity concepts are often interconnected, not always with an explicit acknowledge by diversity scholars, especially within the diversity management literature.

In order to foster an interaction between identity, at the organisational level, and the construction of identity, at the individual level, it worth to try to set a dialogue between gender and identity into DM literature. Setting the boundaries and including minorities implies a relationship between the identity of those who embody the minority population and the organisation (and its boundaries). In this context, it is proposed the term 'liminality' to capture this phenomenon (Van Gennep, 1960; Turner, 1969). Liminality refers to the faintness of the perception on the part of the organisation that condemns that group or individuals to a quasi-invisibility. The recognition of specificity of people, that move from a condition of liminality to its opposite, that is, a condition of acceptance, can be compared to the process of inclusion of those people that move along a continuum from a condition to a new one, and stop in a place in-between (Dentice and Dietert, 2015).

The observation of identity social construction processes (both for individual and for organization), the different ways in which minorities are discriminated within organisations could be interpreted as new ways to foster inclusion processes. Instances of discriminatory acts can be classified in forms of formal discrimination (harassment, insults, acts of violence) or informal discrimination, that is, the set of acts or lack of policies that do not include and protect minorities (Priola et al., 2014). Avoiding both forms of discrimination means fostering the construct of inclusion. A sense of belongingness needs to be accompanied by the fostering of uniqueness. According to Shore et al. (2011) we can assume the concept of inclusion as the result of the relationship between belongingness and uniqueness. Hence, the feeling linked to being part of a group alone is not a sufficient condition in order to make inclusiveness flourish. It does not matter whether an employee occupies a good position in the organisation's chart. What truly matters is that the elements that make that individual unique are involved in decision-making processes.

\section{Conclusion}

As we have seen in the paragraph on gender and identity, performativity is the power of discourse to reproduce the phenomena (Butler, 1993). Through the concept of performativity, Judith Butler addresses the concept of a socially constructed identity into a continuous and iterative way to respect gender norms and expected actions. Identities are not something fixed but something that needs to be done Kelan (2009), thus she conceives how the more relevant is to recognise identity as an outcome of a recognition process, rather than the doer behind the deed' (Kathleen, Rumens and Tyler, 2016). Individual identities are constantly resorting to different ways of displaying and hiding themselves (Ward and Winstanley, 2007), since their social identity is not correctly recognised by others (McLemore, 2015). While the non-recognition of a given social identity may be psychologically disruptive (McLemore, 2015), when an individual's gender identity is accepted, a strong feeling of inclusion is engendered (Rundall and Vecchietti, 2010). Therefore, "acts should not be considered as individual but also as part of shared experiences or collective action, suggesting opportunities for research within organisation" (Jenkins and Finneman, 2017: 8). 
The concept of gender as a social construction within organization has opened new understanding of discrimination and marginalisation in the workplace. In her contribution, Butler considers the binary vision of gender as a source of discrimination, scrutinising also a lack of knowledge as both an effect and a cause of it. The capacity of exploring a distance in the midst of a dichotomy makes the assumption on sex and gender a methodological tool to explore different dichotomies. Beginning with the dichotomy between nature and culture, also explored in the second part of Butler (1999) where, she claims the part of "sex", usually associated with nature, as associated to a prediscursive cultural establishment, helping us to understand even the cultural side of gender, as a repetitive performance (performativity). So doing, Butler opens up new possibilities to explore most of the dichotomies present in organisation studies, as strategy/structure, inclusion/exclusion, tradition/innovation and many others.

\section{Keyword}

Performativity; queer theory; organizational identity; gender.

\section{Reference list}

Albert, S., Whetten, D. A. (1985) "Organizational identity", In Research in organizational behavior, L.L. Cummings and B.M. Staw (eds), pp. 263-295, Vol. 7, Greenwich CT: JAI Press.

Alvesson, M., Ashcraft, K. L., Thomas, R. (2008) "Identity Matters: Reflections on the Construction of Identity Scholarship in Organization Studies", Organization, 15 (1): 5-28.

Alvesson, M., Willmott, H., (2002) “Identity Regulation as Organizational Control: Producing the Appropriate Individual", Journal of Management Studies, 39: 619-644.

Anteby, M., Anderson, C. (2014) "The Shifting Landscape of LGBT Organizational Research", Research in Organizational Behavior, 34: 3-25.

Ashforth, B.E., Mael, F. (1989) "Social Identity Theory and the Organization", Academy of Management Review, 14 (1): 20-39.

Bendl, R., Fleischmann, A., Walenta, C., (2008) “Diversity Management Discourse meets Queer Theory", Gender in Management: An International Journal, 23 (6): 382-394.

Borgerson, J. (2005) "Judith Butler: On Organizing Subjectivities". In Contemporary Organization Theory, Jones, C. and Munro, R. (eds), pp. 63-79, Oxford: Blackwell.

Brown, A.D., Starkey, K. (2000) “Organizational Identity and Learning: A Psychodynamic Perspective", Academy of Management, 25 (1): 102-120.

Butler, J. (1993) Bodies That Matter: On the Discursive Limits of "Sex", London: Routledge.

Butler, J. (1999) [1990] Gender Trouble. Feminism and the Subversion of Identity, New York: Routledge.

Corley, K.G., Spencer, H. (2009) “Generative Organizational Identity Change: Approaching Organizational Authenticity as a Process", In Exploring positive identities and organizations. 
Building a theoretical and research foundation, L.M. Roberts and J.E. Dutton (eds), pp. 361384, London: Routledge.

Danowitz, M., Egger, E., Klarbach, H. (2012) Diversity in Organizations: Concept and Practices, London: Palgrave Macmillan Publishers.

De Souza, E., Brewis, J., Rumens, N. (2016) “Gender, the Body and Organization Studies: Que(e)rying Empirical Research", Gender, Work \& Organization, 23 (6): 600-613.

Dentice, D., Dietert, M. (2015), "Liminal Spaces and Transgender Experience", Theory in Action, 8 (2): 69-96.

Fine, L.E. (2016) "Judith Butler and Leadership: Reimagining intelligibility, social change, and leadership discourse", Journal of Leadership Studies, 10 (2): 69-81.

Fiol, C.M., Huff, A.S. (1992) "Maps for Manager: Where are we? Where do we go from Here?", Journal of Management Studies, 29 (3): 267-285.

Gagné, P., Tewksbury, R. (1998) “Conformity Pressures and Gender Resistance among Transgendered Individuals", Social Problems, 45: 81-101.

Gioia, D.A., Schultz, M., Corley, K.G. (2000) "Organizational Identity, Image and Adaptive Instability", Academy of Management Review, 25 (1): 63-82.

Harding, N. (2007) “On Lacan and the Becoming-ness' of Organizations/Selves”, Organization Studies, 28 (11): 1761-1773.

Hatch, M.J. (2013) Organization theory: Modern, symbolic and postmodern perspective, Oxford: OUP.

Herring, C., Henderson, L. (2012) "From Affirmative Action to Diversity: Toward a Critical Diversity Perspective", Critical Sociology, 38 (5): 629-643.

Jenkins, J., Finneman, T. (2017) “Gender Trouble in the Workplace: Applying Judith Butler's Theory of Performativity to News Organizations", Feminist Media Studies, 1-16.

Kelan, E.K. (2010) "Gender Logic and (Un)Doing Gender at Work", Gender, Work $\mathcal{E}$ Organization, 17 (2): 174-194.

Knights, D. (2015) "Binaries need to shatter or Bodies to matter: Do Disembodied Masculinities undermine Organizational Ethics?", Organization, 22 (2): 200-216.

Laine, P.M., Meriläinen, S., Tienari, J., and Vaara, E. (2016) “Mastery, Submission, and Subversion: On the Performative Construction of Strategist Identity", Organization, 23 (4): 505-524.

McLemore, Kevin A., (2015) "Experiences with Misgendering: Identity Misclassification of Transgender Spectrum Individuals", Self and Identity, 14 (1): 51-74.

Nentwich, J.C., Ozbilgin, M.F., Tatli, A. (2015) “Change Agency as Performance and Embeddedness: Exploring the Possibilities and Limits of Butler and Bourdieu", Culture and Organization, 21 (3): 235-250.

Poggio, B. (2006) “Editorial: Outline of a Theory of Gender Practices", Gender, Work \& Organization, 13 (3): 225-233. 
Priola, V., Lasio, D., De Simone, S., and Serri, F. (2014) “The Sound of Silence. Lesbian, Gay,Bisexual and Transgender Discrimination in 'Inclusive Organizations'", British Journal of Management, 25 (3): 488-502.

Pullen A., Thanem T., Tyler M. (2016) "Sexual Politics, Organizational Practices: Interrogating Queer Theory, Work and Organization", Gender, Work \& Organization 23 (1): $1-6$.

Rhodes, C. (2017) “Ethical Praxis and the Business Case for LGBT Diversity: Political Insights from Judith Butler and Emmanuel Levinas", Gender, Work \& Organization.

Salomon, M.F., Schork, J.M. (2003) “Turn Diversity to your Advantage”, Research-Technology

Management, 46 (1): 37-44.

Schilt, K., Connell, C. (2007) “Do Workplace Gender Transitions make Gender Trouble?", Gender, Work \& Organization, 14 (6): 596-618.

Schilt, K., Westbrook, L. (2009), “Doing Gender, Doing Heteronormativity. 'Gender Normals', Transgender People, and the Social Maintenance of Heterosexuality", Gender $\mathcal{E}$ Society, 23 (4): 440-464.

Scott, S.G., Lane, V.R. (2000) "A Stakeholder Approach to Organizational Identity", Academy of Management Review, 25 (1): 43-62.

Shore, L.M. Randel, A.E., Chung, B.G, Dean, M.A., Ehrhart, K.H., and Singh, G. (2011) "Inclusion and Diversity in Work Groups: A Review and Model for Future Research", Journal of Management, 37 (4): 1262-1289.

Spicer, A., Alvesson, M., Kärreman, D. (2009) “Critical performativity: The Unfinished Business of Critical Management Studies" Human relations, 62 (4): 537-560.

Riach, K., Rumens, N., Tyler, M. (2016) “Towards a Butlerian Methodology: Undoing Organizational Performativity Through Anti-narrative Research", Human Relations.

Rumens, N. (2016a) “Queering Lesbian, Gay, Bisexual and Transgender Identities in Human Resource Development and Management Education Contexts", Management Learning.

Rumens N (2016b) “Towards queering the Business School: A Research Agenda for Advancing Lesbian, Gay, Bisexual and Trans Perspectives and Issues", Gender, Work $\mathcal{E}$ Organization, 23 (1): 36-51.

Rundall, E., Vecchietti, V. (2010) “(In)Visibility in the Workplace. The Experience of Trans Employees in the UK", In Transgender identities: Towards a social analysis of gender diversity, Hines, S., Sanger, T. (eds), pp. 127-150, Oxford: Routledge.

Tatli, A. (2010) "A Multi-layered Exploration of the Diversity Management Field: Diversity Discourses, Practices and Practitioners in the UK", British Journal of Management, 22 (2): 238-253.

Thomas, K.M. (2008) ed., Diversity resitance in organization, New York: Taylor and Francis Group

Turner, V.W. (1969) The ritual process, Chicago: Aldline.

Van Gennep, A. (1960) The rites of passage, Chicago: University of Chicago Press. 
Ward, J., Winstanley, D. (2007) "Sexuality and the City: Exploring the Experience of Minority Sexual Identity Through Storytelling", Culture and Organization, 10 (3): 219-236.

Wickert, C., Schaefer, S.M. (2015) "Towards a Progressive Understanding of Performativity in Critical Management Studies", Human Relations, 68 (1), 107-130. 